\title{
CARACTERIZAÇÃO GEOAMBIENTAL DO DISTRITO DE BONFIM DE FEIRA, FEIRA DE SANTANA - BAHIA, BRASIL
}

\author{
CHARACTERIZATION GEO-ENVIRONMENTAL OF DISTRICT OF \\ BONFIM DE FEIRA, FEIRA DE SANTANA, BAHIA, BRAZIL
}

\section{CARACTERISATION GEO-ENVIRONNEMENTAUX DE LA COMMUNE DE BONFIM DE FEIRA, FEIRA DE SANTANA - BAHIA, BRÉSIL}

\author{
Alisandra de Souza Silva \\ Licenciada em Geografia pela Universidade Estadual de \\ Feira de Santana (UEFS), IC - Fapesb (2006-2008) \\ Rua Lucrécio Novais, 22 - Centro - CEP: 47740-000 \\ Serra Dourada, BA, BR Tel: (77) 3686-2461. \\ E-mail: alisandra.silva@gmail.com
}

Gracinete Bastos de Souza

Doutora em Geotecnia e professora da Universidade

Estadual de Feira de Santana (UEFS)

Km 03, BR 116 - Norte - Campus Universitário - CEP: 44031-460

Feira de Santana - BA, BR Tel: (75) 3224-8086, 3224-8330

E-mail: gracinet@uefs.br

\section{Resumo}

Bonfim de Feira é um distrito de Feira de Santana, que se localiza a $34,4 \mathrm{~km}$ oeste da sede municipal e possui uma população de 3.788 habitantes. Este artigo tem como objetivo apresentar a caracterização geoambiental do referido distrito, com enfoque para o meio físico (geologia, hidrografia, vegetação, geomorfologia, solo, clima e as formas de uso do terreno) e para a situação ambiental (águas superficiais, o estado da vegetação, os processos erosivos e o impacto das atividades humanas no ambiente). Para tanto, realizou-se revisão bibliográfica, levantamento das informações existentes, uso do Sistema de Informações Geográficas (SIG) e trabalho de campo. Neste intuito, foram elaborados mapas das características físicas e geoambientais, identificando-se que os terrenos mais baixos estão nas proximidades do Ribeirão do Cavaco (drenagem principal) e os mais elevados nas Serras da Caboranga e da Mata; as rochas são metamórficas, bastante fraturadas e com textura granítica e granulítica; os solos são 
pouco espessos; e os problemas ambientais mais comuns estão associados com o desmatamento, as cascalheiras, a erosão, o lixo, e o esgotamento a céu aberto. A análise indica a necessidade de saneamento básico e educação ambiental, visando o bem estar e a saúde da comunidade local.

Palavras-chave: Bonfim de Feira, meio físico, situação ambiental.

\begin{abstract}
Bonfim de Feira is district of Feira de Santana city, which is located $34.4 \mathrm{Km}$ from municipal town and it has a 3.788 population. This paper has the main objective is showed the geo-environmental characterization, with enhance to the physical space (geology, hydrology, vegetation, geomorphology, ground, climate and the use of land) and environmental situation (superficial water, the vegetation condition, the erosion and the environmental impact of the human activities) of the place. Hence, we did a bibliographic review, a survey of existing information, a use of the Geographic Information System (GIS) and the visitation in site (in loco). However, were done maps about the physical and geo-environmental; identifying the lands low are near in the Ribeirão do Cavaco (principal drainage) and the lands high in the Caboranga and Mata mountains; the rocks are metamorphic, very fractured and with granitic and granolithic texture, the soils are few thick; the common environmental troubles are associated with the deforestation, the excavation of the gravel, the erosion, the rubbish and the drain on the streets. The analyses show that is necessary the basic sanitation and environmental education for population, it is wishing the well life and health of the people.
\end{abstract}

Key-words: Bonfim de Feira, physical space, environmental situation.

\title{
Résumé
}

Bonfim de Feira est une commune de Feira de Santana, située à 34,4 kilomètres à l'ouest du siège de la municipalité avec une population de 3.788 habitants. Le but de cet article est présenter une caractérisation géo-environnementaux de la commune, avec une attention particulière au milieu physique(géologie, hydrographie, végétation, géomorphologie, sol, climat et les façons d'utilisation du sol) et pour la situation de l'environnement (eaux de surface, l'état de la végétation, le processus d'érosion et de l'impact des activités humaines sur l'environnement). Ainsi, il y a eté faite une revue bibliographique, enquête sur les informations existent, l'utilisation de Systèmes d'Information Géographique (SIG) et de terrain. À cette fin, des cartes avec les caractéristiques physiques et géo-environnementaux ont eté elaborés, oú des terres plus baisses sont à proximité du Ribeirão do Cavaco (le cours d'eau principal) et les plus hauts dans la Serra da Caboranga et Serra da Mata; les roches sont métamorphiques, très fracturées, avec des textures granitique et granulitique; les sols sont légèrement épais; et lês problèmes environnementaux plus fréquents sont associés à la déforestation, les "cascalheiras", l'érosion, les déchets et les égouts à ciel ouvert. L'analyse indique la nécessité de l'assainissement et l'éducation à l'environnement pour le bien-être et la santé de la communauté locale.

Mots-clés: Bonfim de Feira, le milieu physique, la situation de l'environnement. 


\section{Introdução}

Atualmente vêm se intensificando as discussões sobre a questão ambiental, uma vez que estudos recentes sobre esta temática evidenciam que a relação homem-natureza está trazendo sérios problemas ambientais devido ao uso desordenado dos recursos naturais, a exemplo de Araújo e Freire (2008) na APA do estuário do Rio Ceará, em Fortaleza - Ceará, Nascimento et al (2008) na bacia hidrográfica semi-árida do Rio Acaraú, também no Ceará, e Souza et al (2008) na bacia do córrego Tenente em Mariluz, Paraná. Estes estudos constataram expressivas transformações ambientais em tempos históricos, ligadas ao processo de uso e ocupação da terra. Nascimento et al (2008) identificaram sinais de processos de desertificação, Souza et al (2008) concluem que em torno de 20 anos os sinais de degradação são bem evidentes, Araújo e Freire (2008) identificaram sérios problemas ambientais ligados à degradação do manguezal.

A expansão urbana é algo que tem se intensificado nas últimas décadas. Isso provoca uma pressão sobre os recursos naturais, afetando o meio ambiente e a qualidade ambiental dos centros urbanos. Estudos nesse sentido tem sido realizados por Jacobi (2006) em sua obra "Cidade e Meio Ambiente: percepções e práticas em São Paulo", Forattini (1991) com seu estudo sobre a qualidade de vida no meio urbano tendo também a cidade de São Paulo como área de estudo, e Gouveia (1999) que pesquisa a influência da qualidade ambiental na saúde das pessoas.

Jacobi (2006) afirma que o nosso modelo de desenvolvimento conduz a uma degradação ambiental nas cidades e que a falta de políticas públicas é evidenciada pela urbanização predatória sobre o ecossistema. Forattini (1991) assegura que a concentração da população nos centros urbanos além de deteriorar a qualidade de vida das pessoas pode esgotar os recursos da biosfera. Gouveia (1999) certifica que as cidades se tornaram ambientes insalubres devido a tormentos como poluição, pobreza e violência, e acredita que a degradação do ambiente pelo homem tem sido pior nos países mais pobres, uma vez que em muitos casos a urbanização acontece sem planejamento e sem controle.

Dessa maneira, os autores concordam que a urbanização desordenada tende a agredir severamente o meio ambiente e a qualidade de vida das pessoas. Por isso 
estudos ambientais em áreas ainda pouco expandidas podem contribuir para prevenir a degradação ambiental e subsidiar o planejamento socioambiental.

Foi dentro deste contexto que se realizou a caracterização geoambiental de Bonfim de Feira, distrito de Feira de Santana - BA, o qual localiza-se a 34,4 km oeste da sede municipal e perfaz uma área de aproximadamente $40 \mathrm{~km}^{2}$, sendo suas principais vias de acesso as BR 116 Sul, BA 052 (Estrada do Feijão) e BA 861 (Anguera-Feira de Santana). Faz limite com o distrito Governador João Durval Carneiro, com os municípios de Anguera (14km), Serra Preta e Ipecaetá $(15 \mathrm{~km})$ e os distritos de Cavunge - município de Ipecaetá $(16 \mathrm{~km})$, e Poço - município de Antonio Cardoso (4km) (Figura 1). A sua população conforme o censo do IBGE (2000) corresponde a 3.788 habitantes, o que representa $0,79 \%$ do total populacional de Feira de Santana.

O presente trabalho tem como objetivo principal apresentar a caracterização geoambiental do distrito de Bonfim de Feira. As metas incluíram a descrição dos aspectos físicos (geologia, morfologia, solo, hidrografia, vegetação, clima e formas de uso do terreno), e o diagnóstico da situação geoambiental (com destaque para as águas superficiais, o estado da vegetação, os processos erosivos e o impacto das atividades humanas no ambiente).

Espera-se assim contribuir para o planejamento local e do município de Feira de Santana, uma vez que, para planejar e organizar determinado espaço, é preciso conhecer suas limitações e potencialidades. Dessa maneira, fez-se necessário realizar um levantamento das condições ambientais da área de estudo e verificar até que ponto a ação antrópica interfere no meio físico e as consequências dessa ação para a qualidade ambiental do distrito e o bem estar físico e social da população. Busca-se com isso oferecer possíveis subsídios para o planejamento socioambiental da área estudada, uma vez que não existia até o momento qualquer trabalho desta natureza na localidade. 


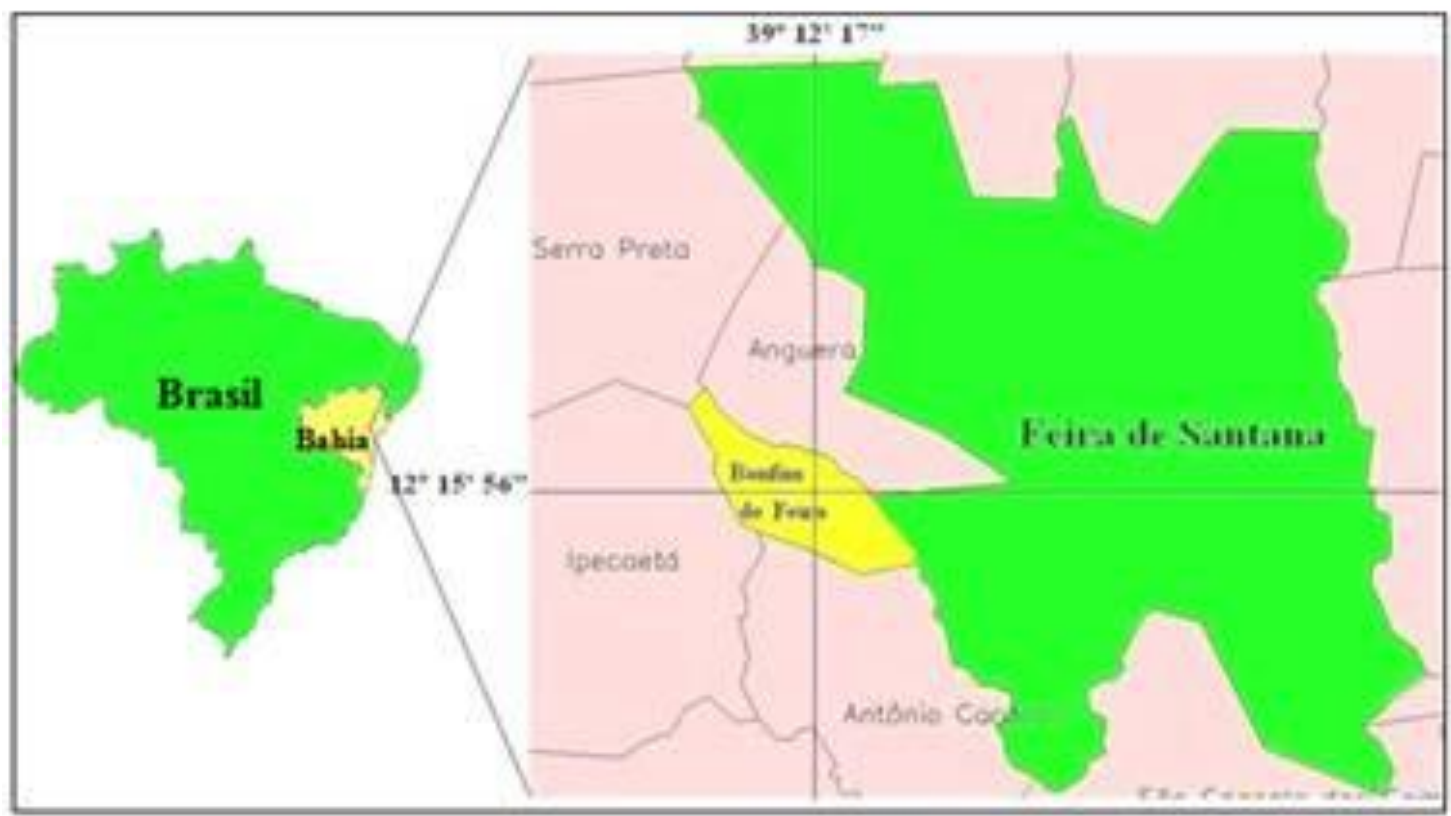

Figura 1 - Feira de Santana e localização do distrito de Bonfim de Feira (SILVA, 2008).

\section{Metodologia}

A metodologia utilizada iniciou-se com revisão bibliográfica (fundamentação teórica sobre o tema) e levantamento das informações pré-existentes sobre a área de estudo, através de consulta à Estação Climatológica da UEFS (83221-INMET/DTEC), a livros, artigos, leis, relatórios anteriores sobre a área, mapas e monografias que serviram de embasamento teórico para o desenvolvimento do trabalho e apresentaram informações sobre a localidade.

Para a elaboração de mapas temáticos e armazenamento de dados, utilizou-se um Sistema de Informações Geográficas (SIG) por meio do "software" SPRING 4.2, desenvolvido pelo Instituto Nacional de Pesquisas Espaciais (INPE).

As atividades de campo foram realizadas entre setembro de 2006 e maio de 2008, onde se pode documentar e identificar in loco a morfologia, o solo, a vegetação, a drenagem, as rochas, as formas de uso do terreno e os efeitos da ação do homem no ambiente (esgotos, lixo, desmatamento, etc.).

Durante essas atividades foram utilizados a folha Santo Estevão (SUDENE, 1977, escala 1:100.000) como base cartográfica, bússola de geólogo, trena, anemômetro, GPS de mão e máquina fotográfica. 


\section{Configuração geográfica da área de estudo}

A morfologia da área estudada se insere na compartimentação de Depressões Periféricas e Interplanálticas: com superfícies de erosão do sertão, relevos planos (pedimentos, glacis, rampas) e relevos residuais isolados ou agrupados. Suas unidades geomorfológicas são compostas por pedimentos funcionais ou retocados por drenagem incipiente (Pe) e serras e maciços residuais (Sr) (CEPLAB, 1980).

A geologia apresenta rochas do embasamento cristalino, integrando o Bloco Jequié (datado do Arqueano), com predomínio de charnoquitos, hornblenda-granulitos, leptitos e anfibolitos (INDA E BARBOSA, 1978 e BARBOSA E DOMINGUEZ, 1996).

No que se refere à hidrografia, a drenagem local faz parte da Bacia do Rio Jacuípe, que escoa para a Bacia do Rio Paraguaçu, que faz parte da Bacia ItapicuruParaguaçu, da Região Hidrográfica do Atlântico Leste (MMA/SRH, 2006). Verifica-se, a partir da Folha Santo Estevão (SUDENE, 1977, escala 1:100.000) e dados de campo, que a drenagem principal é composta pelo Ribeirão do Cavaco, que é intermitente, o mesmo nasce entre as serras da Caboranga e Itaquari, no município de Anguera, e deságua no Rio Jacuípe. Os riachos secundários e também intermitentes são o Riacho da Mussuca e do Cabano. Além desses existem ainda vários canais de drenagem que funcionam como tributários do Ribeirão do Cavaco e dos referidos riachos.

Quanto ao clima, não existem dados referentes à localidade estudada. Porém, do ponto de vista regional, o clima de Feira de Santana se caracteriza como sub-úmido (Am) (conforme a classificação de Koppen) a semi-árido (Dd'A') (classificação de Thorntwaite \& Mather), segundo Pitiá (2004).

Com base no Projeto Radambrasil (1981), a cobertura vegetal é caracterizada como Floresta Estacional Decidual e encontra-se numa área de tensão ecológica com contato estepe (caatinga) - floresta estacional, sendo que essa cobertura está praticamente substituída por agropecuária e pastagem. Em referências recentes, como o mapa dos biomas brasileiros (EMBRAPA, 2007), Bonfim de Feira está inserido no domínio de Caatinga. 
Os solos conforme a EMBRAPA (2006) são do tipo Planossolo e Argissolo Vermelho Amarelo correspondente eutrófico.

\section{Caracterização do meio físico}

O trabalho de campo, que foi realizado em treze saídas onde foi contabilizado um total de 91 pontos coletados, e o levantamento das informações sobre a área permitiram definir as características do meio físico da localidade estudada.

A topografia, com base na Folha Santo Estevão (eqüidistância das curvas de nível de 40m) mostra que o relevo: (a) na parte central do distrito é relativamente plano com cotas em torno de 200 metros; (b) mais acidentado a sudeste na Serra da Mata com cota máxima de 360 metros, e a noroeste na Serra da Caboranga com cotas entre 320 e $570 \mathrm{~m}$ (Figura 2). Numa escala mais local, observa-se que o relevo é suavemente ondulado, com a presença de serras, morros e morrotes, principalmente no setor oeste.

A drenagem dendrítica está marcada preferencialmente de NW para SE, tendo o Ribeirão do Cavaco, o Riacho da Mussuca e o Riacho do Cabano como principais feições fluviais (Figura 3), definindo uma drenagem intermitente. O período de escoamento é principalmente durante a estação chuvosa, sendo que no período seco, alguns tributários não exibem lâmina d'água, e os demais diminuem bastante o nível das águas, o que pode ser intensificado pelo desmatamento da vegetação natural.

Dessa forma, o distrito é abastecido pela água proveniente da rede de distribuição pública municipal. Existe a prática de escavações do terreno para manter a água acumulada durante as chuvas. Assim, verificou-se pequenos açudes, pequenas aguadas e tanques, tanto próximo a zona urbana como na zona rural. 


\section{CATELIÊ GEOGRÁFICO

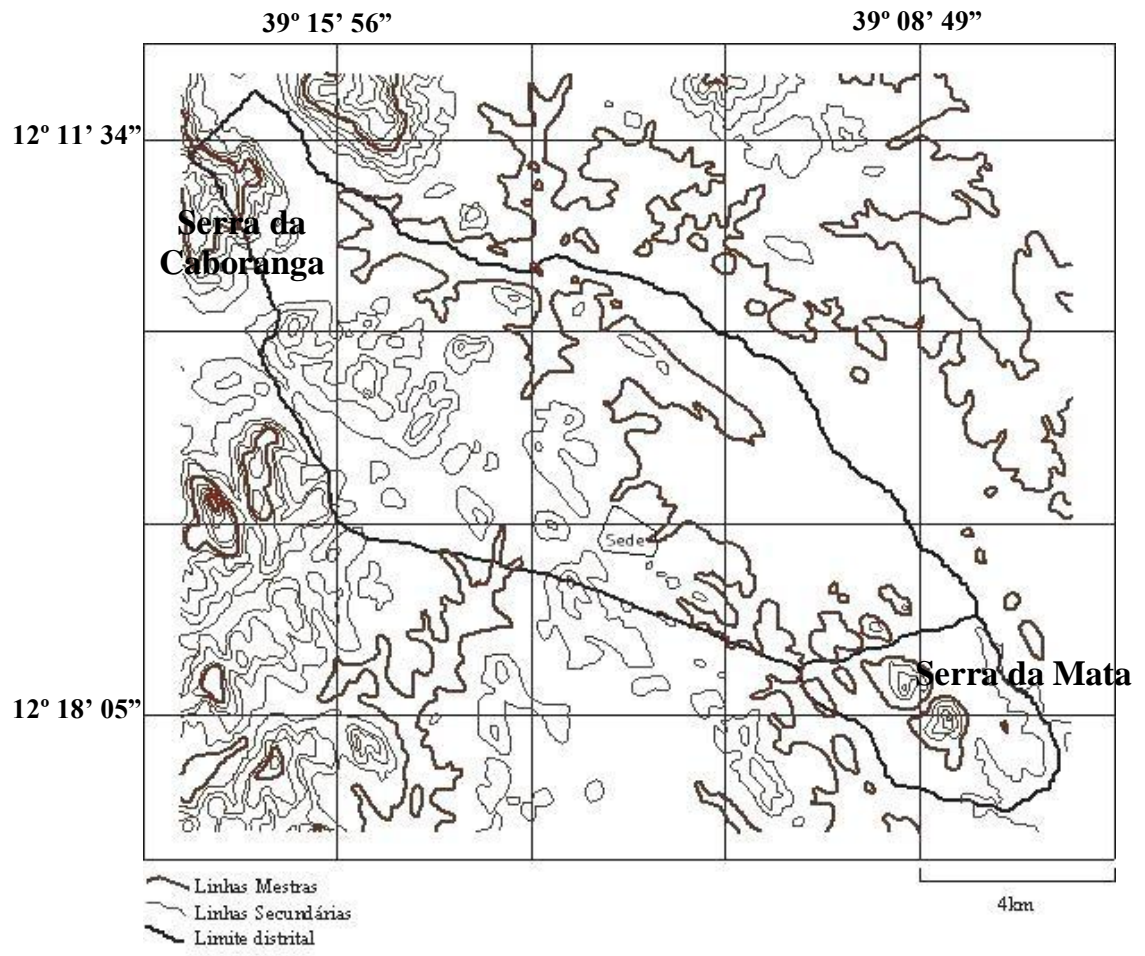

Figura 2 - Distribuição espacial das curvas de nível obtida por meio do Spring 4.2, com base na Folha Santo Estevão (SUDENE, 1977) (SILVA, 2007).

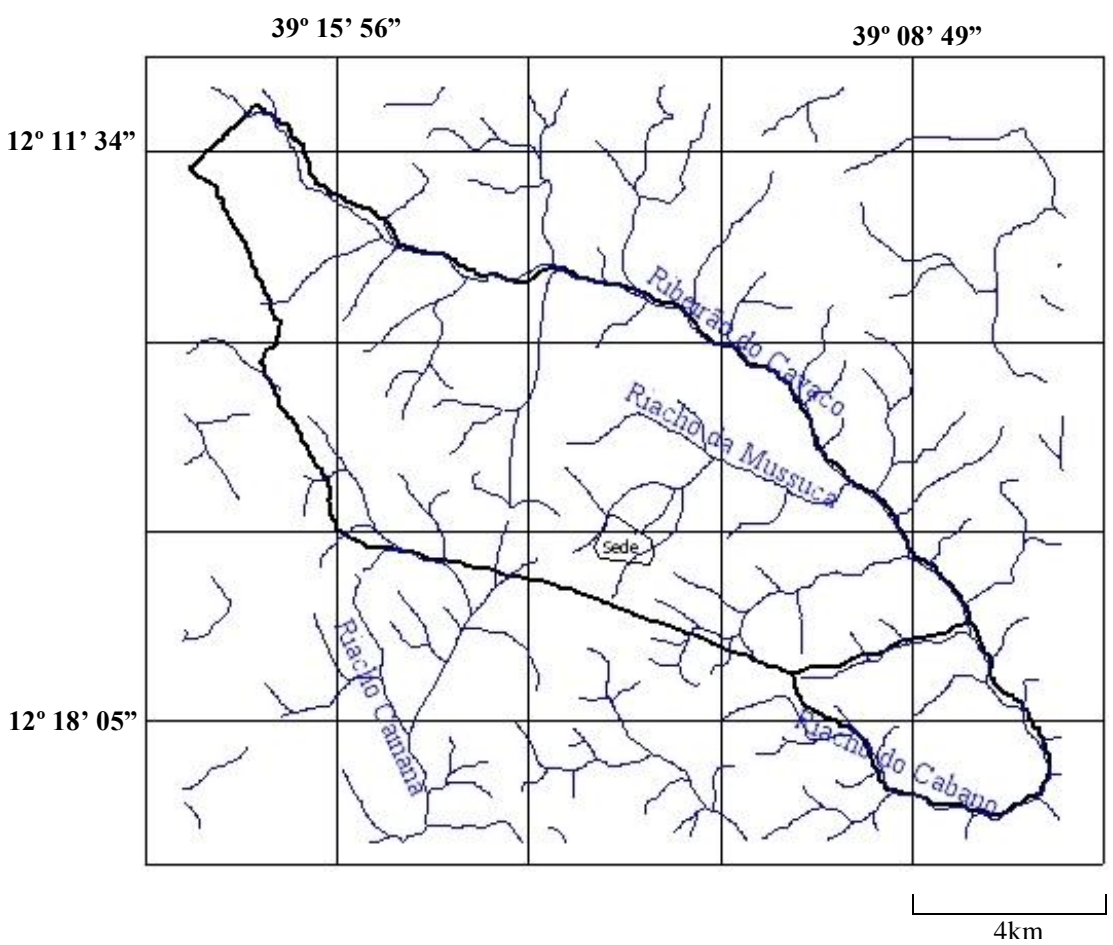

Figura 3 - Distribuição espacial da rede de drenagem obtida por meio do Spring 4.2, com base na Folha Santo Estevão (SUDENE, 1977) (SILVA, 2007). 
Em toda a área do distrito, os afloramentos rochosos são dominantes, sendo que a superfície rochosa varia de sã a alterada, exibindo granulação média a grossa, com minerais de cor laranja, cinza claro a cinza escuro.

Assim, com base em trabalho de campo e em fotografias aéreas (SACS, 1974, escala 1:60.000), se observou que a textura varia de natureza granítica a granulítica, com ocorrência de bandeamento gnáissico, e orientação dos grãos preferencialmente NW-SE, predominando rochas de textura granítica (Figura 4).

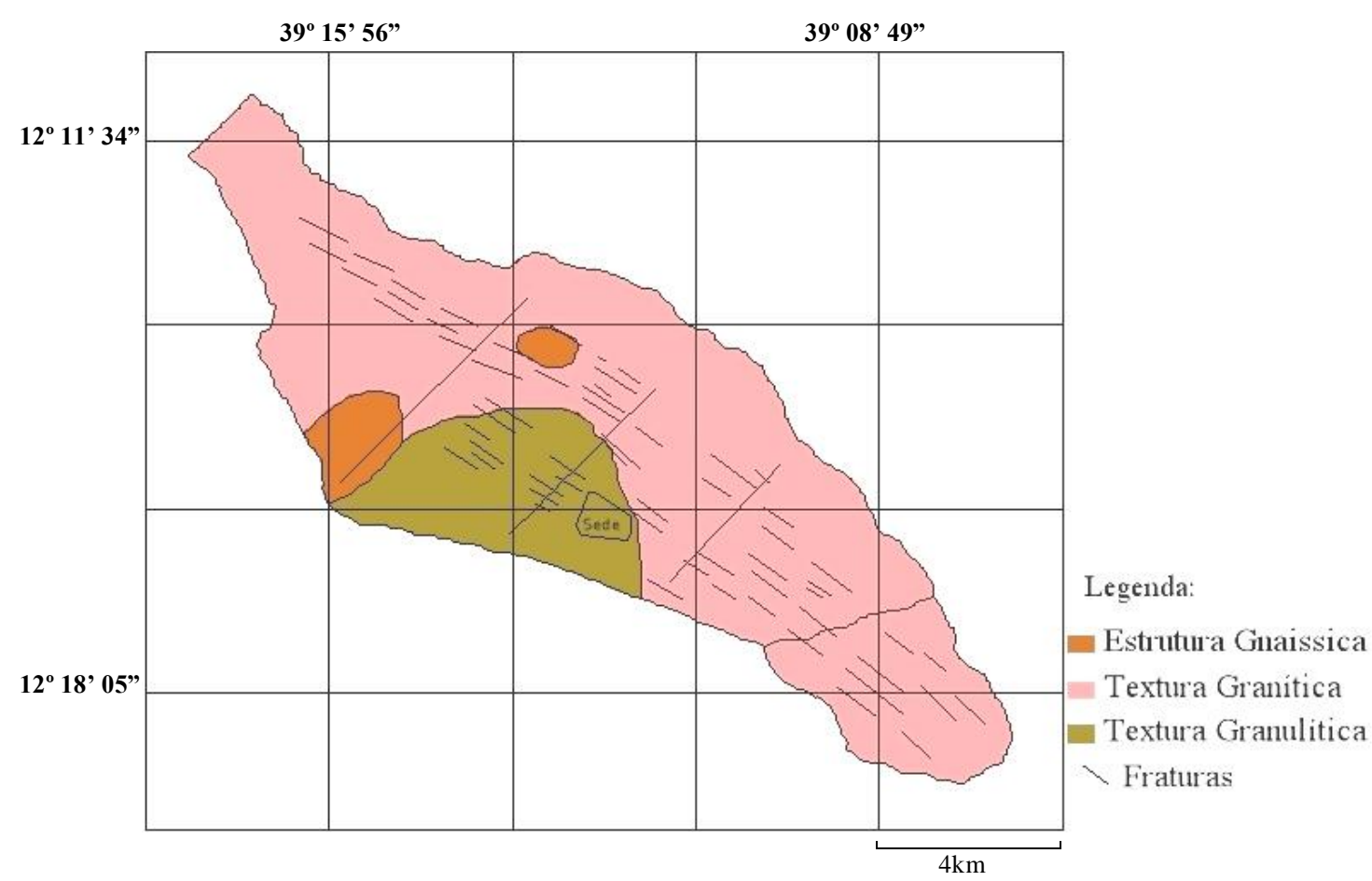

Figura 4 - Distribuição espacial das características geológicas, obtida por meio do Spring 4.2 (SILVA,2008)

A prática do desmatamento é visível na paisagem, por isso a pouca cobertura vegetal restante é composta por herbáceas, arbustos e árvores rasteiras, retorcidas, de pequeno e médio porte, características de caatinga. Sendo que no período de estiagem as plantas perdem as folhas, (como forma de adaptação à perda de água) e o verde visível na vegetação se resume a algumas árvores e cactáceas.

O solo é arenoso e pouco espesso, configurando-se como uma fina camada sobre a rocha. Porém, como exceção, em algumas localidades apresenta profundidades 
maiores $(100 \mathrm{~cm})$. De maneira geral, apresenta características de Neossolo Litólico (observações no trabalho de campo). Esta caracterização não condiz com o mapa de solos da EMBRAPA (2006), provavelmente pela diferença entre as escalas, pois enquanto o mapa da EMBRAPA tem escala 1:130.000, em campo verifica-se os detalhes.

Esse tipo de solo dificulta o desenvolvimento da agricultura, porém, é viável para o desenvolvimento da pecuária, uma vez que, atividades desta categoria não exige profundidade do solo.Assim como facilita as construções antrópicas pelo fato do substrato rochoso se encontrar próximo à superfície, servindo como base sólida consistente. Porém, é necessário fazer um aterro para viabilizar as instalações prediais realizadas no subsolo, o que é mais dificil fazer diretamente na rocha.

Por isso, o uso do terreno é principalmente para pastagem e construções residenciais.

Quanto ao clima local, observa-se que apresenta características de semi-árido, com duas estações definidas: um período chuvoso nos meses de fevereiro, maio, junho, julho, agosto e novembro, com nuvens carregadas e temperatura fisiológica agradável em torno de 23 e $25^{\circ} \mathrm{C}$; e período seco nos outros meses notando-se céu aberto, sol escaldante e temperatura entre 31 e $34,5^{\circ} \mathrm{C}$, medida no termômetro do anemômetro, o qual foi utilizado em campo, e também informações adquiridas na Estação Climatológica da UEFS (83221-INMET/DTEC).

\section{Situação Geoambiental}

\section{Desmatamento}

A área se encontra bastante desmatada em vários pontos, com algumas espécies remanescentes. Isso é algo preocupante, pois, segundo Nascimento et al (2008, p.52) "os desmatamentos aceleram a eutrofização. Os processos erosivos dilapidam as heranças ambientais registradas nas paisagens, produzindo assoreamento dos fundos de vales, desarticulando o ciclo hidrológico e impactando a biodiversidade".

Assim, além de influenciar no micro clima e no conforto térmico, o desmatamento influencia nos processos erosivos, uma vez que a retirada da vegetação deixa o solo exposto e vulnerável ao impacto das gotas de chuva, o que acelera o 
assoreamento dos riachos. Influencia ainda no balanço hídrico, uma vez que a cobertura vegetal funciona como uma importante reguladora hidrológica.

\section{Erosão}

Por erosão entende-se “(...) o processo de desagregação e remoção de partículas do solo ou de fragmentos e partículas de rochas, pela ação combinada da gravidade com a água, vento, gelo e organismos (plantas e animais)" (SALOMÃO E IWASA, 1995 apud INFANTI JR. E FORNASARI FILHO, 1998, p. 134). Assim, a erosão pode ser considerada o processo fragmentação do solo ou de rochas, por meio de agentes como a água (chuva, rios), o vento, o gelo e os organismos, onde pode-se incluir o homem, uma vez que o mesmo impulsiona os processos erosivos.

Nesta perspectiva, a erosão é registrada nas margens de estradas, evidenciadas por sulcos e ravinas com largura de $40,90 \mathrm{~cm}$ e 1,10 metros. São feições erosivas decorrentes da ação das águas de escoamento superficial.

Cabe lembrar os fatores que colaboram para a erosão, no caso da área de estudo, é a inclinação do terreno, a pouca espessura do solo, a textura arenosa do mesmo, a presença de lixo em alguns pontos, o desmatamento e as escavações realizadas pelas cascalheiras. Um dos grandes problemas da erosão para Bonfim de Feira, além das condições das estradas, é o destino final dos sedimentos que são retirados do local pelas enxurradas, os quais são depositados em áreas mais baixas assoreando riachos e lagoas.

\section{Cascalheiras}

Foram encontradas três cascalheiras, áreas de extração de rocha. Uma delas na estrada Bonfim-Cavunge, de 44 metros de diâmetro, onde é retirado fragmentos de rocha, com diâmetro de cascalhos e matacões, para ser usado na manutenção de estradas vicinais que cortam o distrito. Duas cascalheiras mostram-se aparentemente abandonadas, nas proximidades da Fazenda Lírio, a $6 \mathrm{~km}$ da sede distrital, de 7,20 metros de diâmetro, de 8,40 metros de largura e 14,40 metros de comprimento. Todas apresentam profundidade maior que $50 \mathrm{~cm}$.

Essas atividades provocam impactos ao ambiente, pois, riachos foram aterrados pela passagem da máquina, destroem a vegetação local, deixam lixo e quando a 
atividade é encerrada não há uma recuperação do meio físico. Além disso, os grãos são desagregados facilitando o processo de erosão.

\section{Assoreamento \\ $\mathrm{O}$ assoreamento}

(...) consiste na acumulação de partículas sólidas (sedimentos) em meio aquoso ou aéreo, ocorrendo quando a força do agente transportador natural (curso d'água, vento) é sobrepujada pela força da gravidade ou quando a supersaturação das águas ou ar permite a deposição de partículas sólidas. Nos corpos d'água (mares, rios, lagos, etc.), os sedimentos ou partículas são provenientes do material transportado pelo vento, pelo escoamento das águas ou erodido das próprias margens (INFANTI JR. e FORNASARI FILHO, 1998, p. 140).

Portanto, o assoreamento de rios (o qual interessa para este artigo) se caracteriza pela deposição de sedimentos nos seus leitos, influenciados principalmente pela ação da gravidade e de alguns agentes como o vento, o escoamento das águas e a erosão das margens, provocando assim o entulhamento do talvegue.

Assim, em outubro e dezembro de 2007, o Ribeirão do Cavaco e o Riacho da Mussuca, devido à escassez de chuva, encontravam-se com o nível bem abaixo do registrado no mesmo período em 2006, com trechos secos, onde se pode perceber o assoreamento dos mesmos por sedimentos arenosos .

Dessa forma, os riachos no período seco apresentam dificuldades em manter o escoamento, pois, além da mata ciliar ter sido devastada, influenciando na redução da quantidade de água, o entulhamento do talvegue por sedimentos através da erosão, apresenta barreiras à passagem da mesma, e assim, muitos trechos ficam completamente secos, e em outros a água fica parada, como poços d'água.

O desmatamento das matas ciliares é uma constatação da ineficácia da lei, pois, conforme o artigo $2^{\circ}$ da lei federal $n^{\circ} 4.771 / 1965$ (BRASIL, 1965) para todo curso d'água com menos de dez metros de largura (como é o caso dos riachos da área estudada) deveria ser preservado no seu entorno 30 metros da vegetação natural. E conforme o inciso VII do Artigo 215 do cap. VIII da Constituição Estadual (BAHIA, 1989) as matas ciliares são consideradas áreas de preservação permanente. O que de fato não ocorre.

Sede distrital 
Com relação aos problemas ambientais da sede distrital, foram listadas as ruas que apresentam esgoto a céu aberto (dezoito pontos) correspondendo a $64 \%$ do total de ruas, e lixo exposto (sete pontos) correspondendo a $25 \%$. Estes pontos revelam que boa parte das ruas apresenta esgoto a céu aberto, enquanto o lixo exposto encontra-se principalmente nas ruas periféricas (Figura 5). Vale ressaltar que o tipo de esgotamento sanitário em algumas casas é fossa do tipo sumidouro, enquanto as outras lançam os dejetos a céu aberto e em lagoas próximas.

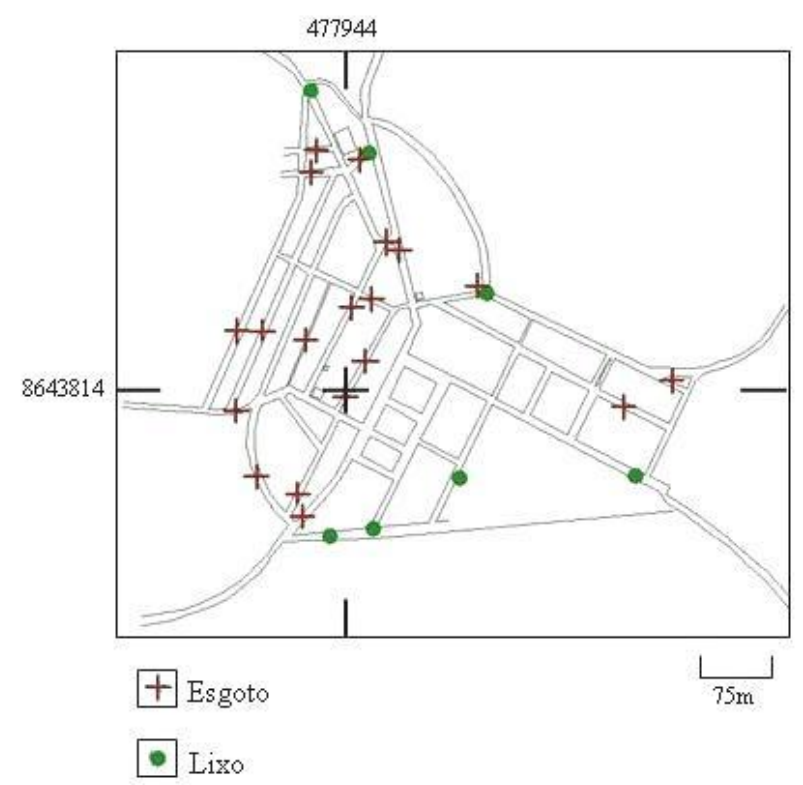

Figura 5 - Distribuição espacial dos pontos de esgoto e lixo exposto na sede distrital obtido por meio do Spring 4.2 (SILVA, 2008).

Logo, verifica-se que há um forte fator de poluição e degradação ambiental, podendo contaminar o solo, os recursos hídricos e as pessoas, tanto pelo contato direto como pela utilização dessas águas para uso doméstico.

Por degradação ambiental entende-se os "processos resultantes de danos ao meio ambiente, pelos quais se perdem ou se reduzem algumas de suas propriedades, tais como, a qualidade ou capacidade produtiva dos recursos ambientais" (BRASIL, DECRETO 97.632/1989).

Já a poluição consiste na

(...) degradação da qualidade ambiental resultante de atividades que direta ou indiretamente: prejudiquem a saúde, a segurança e o bem-estar da população; criem condições adversas às atividades sociais e econômicas; afetem desfavoravelmente a biota; afetem as condições estéticas ou sanitárias do meio ambiente; lancem matérias ou energia em desacordo com os padrões ambientais estabelecidos (BRASIL, LEI 6.938/1981). 
Desse modo, degradação ambiental e poluição estão intensamente relacionadas.

Assim, os problemas que afetam o ambiente, a saúde e a qualidade de vida da população, além da ausência de educação ambiental exigem maiores preocupações das autoridades administrativas, pois, o artigo 225 da Constituição Federal, assegura que

Todos têm direito ao meio ambiente ecologicamente equilibrado, bem de uso comum do povo e essencial à sadia qualidade de vida, impondo-se ao Poder Público e à coletividade o dever de defendê-lo e preservá-lo para as presentes e futuras gerações (Brasil, 1988 p.146).

Ou seja, é direito de todos, assegurado em lei, uma saudável qualidade de vida em equilíbrio com o meio ambiente, o que na realidade não acontece com muitas famílias da área de estudo.

\section{Problemas ambientais}

Dessa maneira, os principais problemas ambientais encontrados no distrito de Bonfim de Feira, foram localizados e georreferenciados espacialmente, sendo gerado, portanto, os pontos da situação ambiental da área de estudo (Figura 6). Além desses problemas, o desmatamento não foi incluso, pois, ocorre em quase todo o território do distrito (Quadro 1).

Com base no quadro 1 , dos problemas registrados, $17,5 \%$ refere-se ao assoreamento, $7,5 \%$ às cascalheiras, $12,5 \%$ são de erosão, $17,5 \%$ são de lixo exposto e $45 \%$ são de esgoto a céu aberto.

Quadro 01 - Evidências dos problemas ambientais de Bonfim de Feira

\begin{tabular}{|c|c|c|}
\hline $\begin{array}{c}\text { Problemas } \\
\text { ambientais }\end{array}$ & Evidências & Quantidade \\
\hline Assoreamento & $\begin{array}{c}\text { Deposição de sedimentos arenosos no leito dos } \\
\text { riachos. }\end{array}$ & 07 pontos \\
\hline Cascalheiras & Retirada de rocha britada através de máquinas. & 03 pontos \\
\hline Erosão & Presença de sulcos e ravinas nas bordas de estradas. & 05 pontos \\
\hline $\begin{array}{c}\text { Esgoto a céu aberto, } \\
\text { lixo exposto e } \\
\text { atividades humanas }\end{array}$ & $\begin{array}{c}\text { Ruas na sede distrital e nos seus arredores, onde se } \\
\text { identificou a presença de lixo, } \\
\text { esgoto, }\end{array}$ & $\begin{array}{c}07 \text { pontos } \\
\text { construções antrópicas e criação de animais. }\end{array}$ \\
\hline Desmatamento & $\begin{array}{c}\text { Erosão, assoreamento, grandes áreas de pastagem, } \\
\text { cascalheiras e atividades humanas. }\end{array}$ & Sem dimensionamento \\
\hline
\end{tabular}




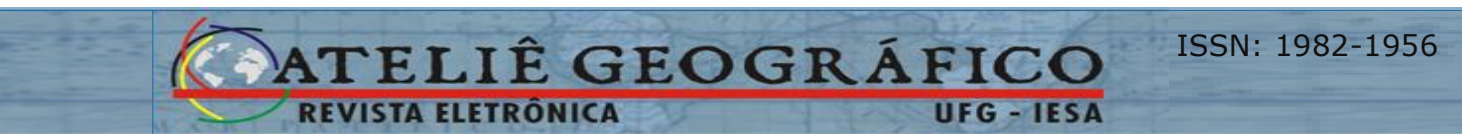
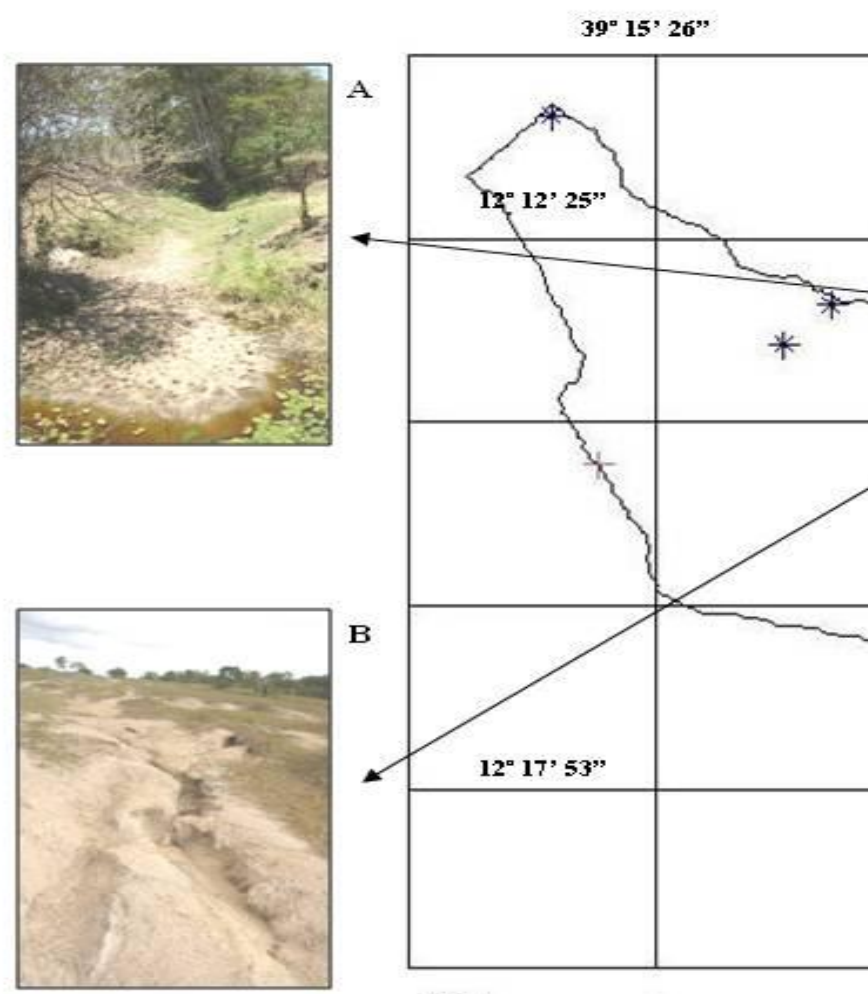

橉 Assoreamento $\boxplus$ Cascallheiras Erosão

- Erosão e lixo exposto

39. 08' 49"

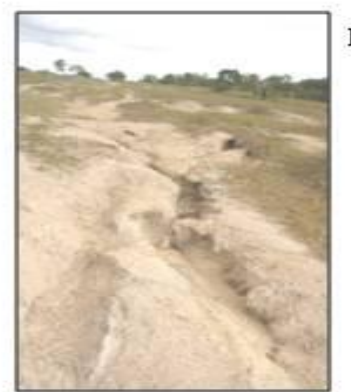

$\square$ Esgoto a céu aberto, lixo exposto

Figura 06 - Situação ambiental de Bonfim de Feira: (A) Ribeirão do Cavaco (Out/2007); (B) proximidades do monte (Mai/2008); (C) Rua Augusto Moreira Bastos (Dez/2007); (D) Proximidades da Fazenda Lírio (Mai/2008); (E) Fundo da Rua Elmiro Borges Freitas com a Rua Teódulo Bastos de Carvalho (Ago/2007) (SILVA, 2008). 
Nosso estudo em Bonfim de Feira, tal qual visualizaram Araújo e Freire (2008), Nascimento et al (2008), e Souza et al (2008) em outros locais, identificou que as principais causas dos problemas ambientais estão associados com a expansão urbana desordenada e uso irracional dos recursos naturais. $E$ aqui sumariamos: o desmatamento, o desmonte de rocha e falta de saneamento. Inicialmente, imaginávamos que a área do distrito e o total da população indicariam irrisórios problemas ambientais, porém registramos o contrário. Portanto, é incompreensível que uma população tão pequena já esteja vivenciando esta situação.

Assim, observa-se que muito ainda há que se fazer para melhorar a qualidade ambiental da área em questão, através de políticas públicas e pelo processo de educação ambiental o que é determinado em lei tanto na legislação federal quanto estadual e municipal, pois, o artigo $2^{\circ}$ da lei federal $n^{\circ} 6.938 / 1981$ (BRASIL, 1981) afirma que se deve promover a "educação ambiental a todos os níveis de ensino, inclusive a educação da comunidade, objetivando capacitá-la para participação ativa na defesa do meio ambiente".

E como complemento desta lei, o artigo $1^{\circ}$ do decreto federal afirma que se deve

orientar a educação, em todos os níveis, para a participação ativa do cidadão e da comunidade na defesa do meio ambiente, cuidando para que os currículos escolares das diversas matérias obrigatórias contemplem o estudo da ecologia (BRASIL, DECRETO 99.274/1990).

Já o artigo 214 do capítulo VIII da Constituição Estadual (BAHIA, 1989) afirma que é dever do Estado e dos municípios "Promover a conscientização pública para a proteção do meio ambiente e estabelecer programa sistemático de educação ambiental em todos os níveis de ensino e nos meios de comunicação em massa”.

E a Lei Complementar do município no seu artigo 34 assegura que:

\begin{abstract}
A educação ambiental será promovida: (I) na rede escolar do município, através de atividades extracurriculares e através de conteúdo de programas que despertem, nas crianças a consciência de preservação do meio ambiente, conforme programa a ser elaborado pela Secretaria Municipal de Educação; (II) junto à comunidade pelos meios de comunicação e através de atividades dos órgãos e entidades do município (FEIRA DE SANTANA, LEI COMPLEMENTAR 1.612/1992, p.11).
\end{abstract}

Portanto, cabe aos órgãos públicos, associados com Universidades e outras entidades, promoverem um processo intenso de educação ambiental nas escolas e na 
comunidade local, para que todos tenham conhecimento da importância de se preservar o ambiente e os benefícios que esta prática garante para o equilíbrio ecológico e para o bem estar da população. E juntamente com isso, é fundamental que as autoridades administrativas se movam na melhoria da infra-estrutura urbana, com a construção de fossas sépticas para as famílias carentes, ou esgotamento sanitário das águas servidas (fazendo o tratamento desse efluente líquido), e intensificando o recolhimento do lixo no distrito, para que possa se garantir uma boa qualidade de vida para a população local.

\section{Conclusão}

Diante do exposto pode-se dizer que Bonfim de Feira está inserido numa região semi-árida, de vegetação predominantemente caatinga e embasamento cristalino, com grande quantidade de afloramento de rocha tipo metamórfica, bastante fraturadas. $\mathrm{O}$ relevo numa escala local é suavemente ondulado, o que foi perceptível no campo, e em uma escala de 1:100.000 apresenta poucas ondulações no setor leste, e é mais acidentado a sudeste e a oeste.

Com relação a hidrografia, todos os riachos da localidade são intermitentes, por isso alguns tributários não exibem lâmina d'água no período seco, e os outros diminuem bastante o nível das águas. O solo é pouco espesso.

Deste modo, pode-se dizer que a topografia, a natureza das rochas, a espessura do solo, o caráter intermitente da drenagem e o clima, dificultam o desenvolvimento da agricultura e a expansão dos agrupamentos populacionais. Por isso, as pastagens e a cultura de gado e caprinos são as formas mais comuns de uso do terreno, a despeito da cultura de fumo, mandioca, milho e feijão.

Assim sendo, acredita-se que o meio físico influenciou no processo de ocupação e apropriação do espaço assim como na qualidade de vida das pessoas e no desenvolvimento local e regional. Por isso, faz-se necessário atentar para as intervenções humanas que sejam irracionais podendo levar ao comprometimento do meio ambiente fisico e social.

Pode-se constatar também alguns problemas ambientais na área de estudo, com destaque para: o desmatamento, o assoreamento dos corpos d'água, a erosão, as cascalheiras, e a poluição na sede distrital por lixo e esgoto doméstico. 
Dessa forma, verifica-se que algumas práticas humanas realizadas na localidade são nocivas ao meio ambiente e precisam ser revistas, pois a degradação ambiental é algo que afeta o meio físico como um todo e a qualidade de vida da população, a qual muitas vezes não tem conhecimento do impacto de suas atividades sobre o próprio bem estar. Assim, reafirma-se a necessidade de um trabalho de educação ambiental na área de estudo e melhoria da infra-estrutura urbana.

Portanto, considera-se que a caracterização realizada permitiu a compreensão do meio físico e da situação ambiental do distrito de Bonfim de Feira, ajudou a entender que as futuras ocupações devem passar pelo conhecimento das condições físicas e ambientais da área de estudo, e espera-se que esta caracterização possa auxiliar as autoridades competentes a melhorar a qualidade de vida da população, uma vez que até então não existia um trabalho desta natureza na localidade.

\section{Referências Bibliográficas}

ARAÚJO, M. V., FREIRE, G. S. S. Análise ambiental e de uso e ocupação da Área de Proteção Ambiental do estuário do Rio Ceará, Fortaleza - Ceará. Revista de Geologia, Fortaleza, v. 21, n. 1, p. 7-19, 2008. Disponível em:

<http://www.revistadegeologia.ufc.br/01_2008.pdf>.Acesso em: 18 maio 2009.

BAHIA. Constituição (1989). Constituição do Estado da Bahia, promulgada em 05 de outubro de 1989. Disponível em: 〈http://www.ba.gov.br>. Acesso em: 18 dez. 2007.

BARBOSA, J. S. F.; DOMINGUEZ, J. M. L. Mapa Geológico do Estado da Bahia: texto explicativo. Salvador: Secretaria da Indústria, Comércio e Mineração, Superintendência de Geologia e Recursos Minerais, 1996. 1 mapa: color. Escala 1:1000.000.

BRASIL. Constituição (1988). Constituição: República Federativa do Brasil 1988. Brasília: Senado Federal, 292 p. 
Lei $\mathbf{n}^{0}$ 4.771, de 15 de setembro de 1965. Institui o novo código

florestal. Disponível em:

<http://www.mma.gov.br/port/conama/legiabre.cfm?codlegi=311>.Acesso em: $17 \mathrm{dez}$. 2007.

Lei $\mathbf{n}^{0} 6.938$ de 31 de agosto de 1981. Dispõe sobre a Política Nacional do Meio Ambiente, seus fins e mecanismos de formulação e aplicação, e dá outras providências. Disponível em:

<http://www.mma.gov.br/port/conama/legiabre.cfm?codlegi=313>. Acesso em: $10 \mathrm{dez}$. 2007.

Decreto $n^{\circ} 99.274$ de 6 de junho de 1990. Regulamenta a Lei $n^{\circ} 6.902$, de 27 de abril de 1981, e a Lei n ${ }^{\circ}$ 6.938, de 31 de agosto de 1981, que dispõem, respectivamente sobre a criação de Estações Ecológicas e Áreas de Proteção Ambiental e sobre a Política Nacional do Meio Ambiente, e dá outras providências. Disponível em: <http://www.mma.gov.br/port/conama/legiabre.cfm?codlegi=328>. Acesso em: $10 \mathrm{dez}$. 2007.

.Decreto $\mathrm{n}^{\mathbf{0}} \mathbf{9 7 . 6 3 2}$ de 10 de abril de 1989. Dispõe sobre a regulamentação do Artigo $2^{\circ}$, inciso VIII, da Lei $n^{\circ}$ 6.938, de 31 de agosto de 1981, e dá outras providências. Disponível em: <http://www.planalto.gov.br/ccivil_03/decreto/1980-1989/D97632.htm>. Acesso em: 20 dez. 2007.

CEPLAB, Centro de Planejamento da Bahia. Mapa Geomorfológico do Estado da Bahia. Salvador: Secretaria de Planejamento, Ciência e Tecnologia, 1980. 1 mapa: color., $116 \mathrm{~cm}$ x 107cm. Escala: 1:1000.000.

EMBRAPA. A Embrapa nos Biomas Brasileiros. Disponível em: <http://www.embrapa.gov.br>. Acesso em: 14 mar. 2007.

EMBRAPA SOLOS. Solos do Nordeste. UEP: Recife, 2006. Disponível em: <http://www.uep.cnps.embrapa.br/solos/>. Acesso em: 26 mar. 2007.

FEIRA DE SANTANA. Lei Complementar no 1.612 de 12 de dezembro de 1992. Institui o Código do Meio Ambiente e dispõe sobre o Sistema Municipal do Meio Ambiente para a administração da qualidade ambiental, proteção, controle e desenvolvimento do meio ambiente e uso, adequado dos recursos naturais no Município de Feira de Santana. Prefeitura Municipal de Feira de Santana, 1992. 
IBGE (Instituto Brasileiro de Geografia e Estatística). Dados Censitários, 2000. Disponível em: <http://www.sidra.ibge.gov.br/bda/tabela/protabl.asp?z=t\&o=3\&i=P>. Acesso em: 31 jul. 2006.

INDA, H.A.V.; BARBOSA, J.F. Mapa Geológico do Estado da Bahia. Salvador: Secretaria das Minas e Energia, 1978. 1 mapa: color., $120 \mathrm{~cm}$ x $106 \mathrm{~cm}$. Escala 1: 1000.000 .

INFANTI JUNIOR, N. \& FORNASARI FILHO, N. Processos de Dinâmica Superficial. In: OLIVEIRA, A.M.S. \& BRITO, S.N.A. (Eds.). Geologia de Engenharia. São Paulo: Associação Brasileira de Geologia de Engenharia (ABGE), 1998. cap. 9, p.131-152.

MINISTÉRIO DO MEIO AMBIENTE, SECRETARIA DE RECURSOS HÍDRICOS. Caderno da Região Hidrográfica Atlântico Leste. Brasília: MMA, 2006, 156p.

NASCIMENTO, F. R. do, et al. Diagnóstico Geoambiental da bacia hidrográfica semiárida do Rio Acaraú: subsídios aos estudos sobre desertificação. Boletim Goiano de Geografia, Goiânia, v. 28, n. 1, p. 41-62, jan/jun. 2008. Disponível em: <http://www.revistas.ufg.br/index.php/bgg/article/view/4900/4106>. Acesso em 18 maio 2009.

PITIÁ, A.M.de.A. Caracterização do meio físico do distrito de Bonfim de Feira, Feira de Santana - Bahia. 2004. 14 folhas. Relatório (iniciação científica) Universidade Estadual de Feira de Santana, Feira de Santana, 2004.

PROJETO RADAMBRASIL. Mapa de Vegetação, Folha SD.24. Ministério das Minas e Energia:1981. 1 mapa color. Escala 1: 1000.000.

SACS. 1974. Escala 1:60.000.

SILVA, A. de S. Diagnóstico Geoambiental do distrito de Bonfim de Feira, Feira de Santana - Bahia. 2008. 41 folhas. Relatório final (iniciação científica FAPESB/UEFS). Universidade Estadual de Feira de Santana, Feira de Santana, 2008.

Caracterização do Meio Físico do Distrito de Bonfim de Feira, Feira de Santana - Bahia. 2007. 38 folhas. Relatório final (iniciação científica FAPESB/UEFS). Universidade Estadual de Feira de Santana, Feira de Santana.

SOUZA, M. L. de, et al. Diagnóstico geoambiental da bacia do córrego Tenente em Mariluz, Paraná, Brasil. Revista Brasileira de Geociências, v. 38, n.2, p. 379-391, jun. 2008. Disponível em <http://ojs.c3sl.ufpr.br/ojs2/index.php/rbg/article/viewFile/9107/9300>. Acesso em: 18 maio 2009. 
SUDENE. Folha Santo Estevão SD.24-V-B-III. 1977. 1 carta: color. Escala 1: 100.000 .

UNIVERSIDADE ESTADUAL DE FEIRA DE SANTANA. Estação Climatológica 83221- INMET/UEFS/DTEC.

Recebido para publicação em julho de 2009

Aprovado para publicação em dezembro de 2009 